\title{
The Relationship of Self-efficacy Beliefs, Writing Strategies, and the Correct Use of Conjunctions in Iranian EFL Learners
}

\author{
Nader Assadi Aidinlou \\ Postgraduate Department of English Language and Linguistic, IAU, Ahar Branch, Azarbaijan, Iran \\ E-mail: naderasadi@yahoo.com \\ Leila Masoomi Far (Corresponding author) \\ Department of ELT, Ahar Branch, Islamic Azad University, Azarbaijan, Iran \\ E-mail: masoomifar_leila@yahoo.com
}

Received: 02-03- 2014

Accepted: 09-04- 2014

Published: 01-07- 2014

doi:10.7575/aiac.ijalel.v.3n.4p.221

URL: http://dx.doi.org/10.7575/aiac.ijalel.v.3n.4p.221

\begin{abstract}
The present study was an attempt to investigate the relationship of self-efficacy beliefs, writing strategies, and correct use of conjunctions in EFL learners. The participants were 67 EFL learners who studied English in Iran English Institute, Karaj branch. Participants filled out two questionnaires including Self-efficacy beliefs questionnaire, and Writing strategies questionnaire. They also had a writing task in form of completion regarding conjunctions. The results indicated that there was a significant relationship between self-efficacy beliefs and writing strategies of EFL learners, but there was not a significant relationship between the writing strategies and correct use of conjunctions in these learners.
\end{abstract}

Keywords: Self-efficacy beliefs, writing strategies, conjunctions.

\section{Introduction}

Almost recently, the area of individual differences in language learning like learning styles, learning strategies, and use of different strategies in language learning contexts has attained a great deal of attention. Education is no longer viewed classically as an activity specified for young people.

And schools are in charge of equipping their students for lifelong learning. On the other hand, writing skill as a way for transforming knowledge and information has assigned an important position to itself. In order to attain proper writing skill, several writing strategies have been investigated which being familiar with them and using them appropriately helps the learner to become a successful writer

Furthermore, language learners also vary in other aspects and issues like the amount of control, direction or regulation of the mental procedures which are required for language learning and also in their beliefs about achieving success in a particular task. In the past few years, self-directed learning has become one of the critical issues which have appeared in educational psychology.

Boekaerts (1999) declared that self-regulation is effective in understanding learning procedures in the educational contexts, and because of that, investigating the dynamics and results of this central and impressive issue has useful implications for establishing proper educational atmospheres. According to Zimmerman and Schunk (2008) there is a mutual relation between the level of self-regulation and the self-efficacy beliefs. While learners improve their level of self-regulation, they also improve their self-efficacy beliefs, and vice versa: the existence of self-efficacy beliefs helps learners to confront new, self-regulated learning contexts.

Bandura (1977) proposes that one of the main aspects of self-efficacy is the learner's belief about the self-regulatory efficacy. Putting it in another way, students will come to better achievements if they believe that their performance is good in managing their cognitive strategies in a fruitful way. So students who benefit high levels of self-efficacy will have higher motivation in accomplishing the tasks and in educational context.

Different authors at different times have attempted to classify learning strategies in classes for their study. An early classification is Weinstein and Mayer's (1986) with the framework of self-regulated learning theory that includes rehearsal, elaboration, organization, comprehension, monitoring, and affective strategies. Furthermore, the study of writing strategies is regarded as part of a research movement named "process writing", which focuses on gaining insight about the mental processes which writers engage in while composing.

\subsection{Significance of the Study}

This study is going to investigate the possible co-relationships between EFL learners' self-efficacy beliefs, their use of writing strategies and the correct use of conjunctions with the hope of better realizing the interaction existing among these variables and making predictions about them. 
If the results show that learners who have high self-efficacy beliefs are more aware of the writing strategies and their use of conjunctions are better than the others, the next step might be to find ways to help EFL learners to increase their self-efficacy beliefs to have better participation in the process of language learning and to become more motivated in the process of learning. The findings of this study would allow us to predict learners' writing strategies and use of conjunctions and can help teachers to foster their students' writing skills in EFL contexts.

Furthermore, when the amount of use of writing strategies and the percentage of correct use of conjunctions are revealed, teachers can devise writing tasks which are more useful for the learners and can improve the learning process.

\subsection{Statement of the Problem}

Self-efficacy beliefs are regarded as a critical issue in cognitive psychology related to the cognitive, motivational, and social-contextual factors which is an explanation for learning. This important issue is used to investigate the characteristics of learners that impress fruitful learning and education.

In literature it is generally believed that one important issue of self-regulated learning is the learners' ability to choose the proper strategies needed and mix them so that they lead to effective and successful learning. Indeed, research and studies investigating the role of learning strategies in educational attainments (Hartley \& Branthwaite, 1989; Khaldieh, 2000; Torrance et al., 2000) displays that high achievers show higher use of all strategies than low achievers.

Although individual differences in the domain of special styles and strategies in L2 learning atmospheres, and writing strategies research have been well documented before, but few investigations have considered the relationship between learners' self-efficacy and their writing strategies. To be more specific, in this study the researcher intends to investigate first, the possible relations between Iranian EFL learners' self-efficacy beliefs and their writing strategies and then to find the relationship between writing strategies and the correct use of conjunctions in writing tasks.

\subsection{Research Questions}

To fulfill the purpose of this study, the following questions were raised:

$\mathbf{R Q \#} 1$ Is there a significant relationship between EFL learners' self-efficacy beliefs and writing strategies?

RQ\# 2 Is there a significant relationship between EFL learners' writing strategies and their correct use of conjunctions in writing tasks?

\section{Review of Literature}

\subsection{Self-efficacy}

Zimmerman (1990) proposed some properties which constitute the beliefs in self-efficacy (p 6). They are mainly:

- Self-efficacy is composed of judgments about the learner's own merits and abilities to accomplish tasks. It is supposed as an integral side of self-concept, but of course it is not regarded as a synonym for self-concept.

- Self-efficacy beliefs are considered multidimensional and are related to particular fields and parts.

- The amount of self-efficacy is directly related to the special context at hand.

- Measuring of self-efficacy beliefs depends highly on the assessment of the accomplishment fluency than the regulation and monitoring criteria. The perception of the capacity to confront an accomplishment is more proper when its basis is on the earlier experiences received from similar accomplishments, and it is the opposite of the context in which the experience is obtained through comparing the accomplishment of others.

- Clarifying the amount of self-efficacy is a kind of internal procedure which is established before the beginning of a task. So learners should be aware of the features of the task under accomplishment in order to be able to make decisions about its self-efficacy.

However, Bandura (1999) stated that self-efficacy beliefs are constituted both before and after a particular activity. For instance, when learners confront a specific activity with high self-efficacy beliefs, their result will be better if the level of their self-efficacy beliefs is low. The same situation will be when the learners on the basis of their belief of success or failure for accomplishing an activity, try to establish an increase or decrease in the amount of their self-efficacy beliefs while confronting that specific activity (Ilgen and David, 2000).

Investigations about self-regulated learning which have been done recently have shed light on the importance of selfefficacy beliefs. Bandura (1977) presented a definition for self-efficacy as the beliefs about one's abilities and merits to classify and accomplish the activities necessary for producing special achievements. In a context in which achievement is considered a critical issue, it consists of learners' confidence and belief in their cognitive skills to acquire or execute the academic process. Bandura declared that the beliefs regarding self-efficacy are not either universal personality characteristics or usual self-concept but rather they are considered as particular self-conceptions which learners develop especially from their previous successes and failures in various tasks confronted before.

Zimmerman and Bandura (1994) registered the results of an investigation in which self- efficacy for self-regulation was related to self-efficacy for achievement. So it shows that the learners who believed in their capabilities to attain also believed in their capabilities to self-regulate. Pintrich (1999) reported that learners who were more efficacious about their capability to accomplish well in a specific activity or task were regarded to be better cognitively involved in attempting to learn the course issues compared to those who were reported low in efficacy. 


\subsection{Writing Strategies}

Torrance (2000) declared that writing strategy is the sequence in which a writer engages in planning, composing, and revising activities and tasks related to writing. Writing strategies can be defined as those processes involved by the writer to (1) manage and control the online direction of goals, (2) compensate and modify the limited capability of human cognitive abilities and resources and (3) overcome the problems confronted by the writers (Torrance \& Jeffery, 1999).

For describing writing strategies there are various categorizations proposed by different investigators and writers. For example, some investigators (Hirose \& Sasaki, 1994) have proposed a three-factor structure which is composed of these three factors: planning, formulation and revising. Other researchers have defined a four-factor structure namely: planning, monitoring, evaluating and resourcing (Victori, 1997), and there are still other classifications like the sixfactor classification consisting of memory-related, cognitive, compensation, metacognitive, social and affective strategies (Khaldieh, 2000) that is based on Oxford's (1990) taxonomic approach.

\subsection{Conjunctions}

Conjunctions are language resources that produce connectedness in the text. Thompson (2004 as cited in Pandian \& Asadi, 2010), stated that conjunction takes place at three levels. They are mainly within the clause by the use of prepositions, between clauses by use of coordinators or subordinators and between clause complexes or sentences by means of conjunctive adjuncts.

Martin (1992) classifies conjunctions into two groups of external and internal conjunctions. External conjunctions are concerned with the logical organization of a field. It can be seen as the sequences of activities. On the other hand, internal conjunctions are concerned with the logical organization of discourse especially in the written mode and they are basically cohesive. These internal conjunctions are the ones at the center of attention of this paper.

\section{Methodology}

\subsection{Participants}

A total of 67 EFL learners who studied English in Iran English Institute, Karaj branch served as the participants of this study. This sample was selected through the cluster random sampling. The participants were both male and female, and they were between 18 to 24 years old. They were studying in advanced level of Iran Institute. After selecting the sample, they were asked to answer two questionnaires including Self-efficacy questionnaire, and Writing Strategies Questionnaire. They also had a writing task in form of completion regarding conjunctions.

\subsection{Instrumentation}

The data for this study was collected through a "Self-efficacy Questionnaire" which was based originally on selfregulation trait questionnaire of O'Neil \& Herl (1998) (see Appendix). The questionnaire includes 32 items measuring four constructs, mainly Planning, Self-checking, Effort, and Self-efficacy. For the purpose of this study the items related to self-efficacy were chosen and modified by the researcher to be suitable for the context under investigation. Selfefficacy is assessed through 8 items regarding self-efficacy beliefs. The questionnaire was validated by Dehghan (2005) for the first time in Iran. This questionnaire is in the form of "Likert Scale" asking the participants to select from five options:

\section{1- Almost Never, 2- Seldom, 3- Sometimes, 4- Often, 5- Almost Always.}

The other questionnaire used was the writing strategies questionnaire adopted from the Language Strategy Use Inventory by Cohen, Oxford and Chi (2002). There are ten statements for writing language skill. This instrument has a strong reliability level as the Cronbach's alpha coefficient is .91 (Yoong 2010). This questionnaire is also in the form of 5-point Likert scale ranging from 1 to 5. The 5-point Likert scale is (1) Never true of me, (2) Usually not true of me, (3) Sometimes true of me, (4) Usually true of me and (5) Always true of me.

A writing completion task was also used in order to investigate the percentage of correct use of conjunctions in the writing skill of EFL learners. For this purpose a piece of writing was selected from IELTS Preparation Writing Book (Ghaemi, 2009). The conjunctions were omitted from the passage and the students were asked to complete the written task with the correct ones.

\subsection{Design}

This study drew on the descriptive research design. The descriptive design was considered appropriate since, as Adams and Schvaneveldt (1985) states, it is a kind of research in which the main goal is to show an accurate profile of persons, events, or objects. The approach used for data collection was the survey approach. The main characteristic of survey is the gathering of data from a sample or specific population by means of questionnaires or interview. In this approach the researcher does not manipulate independent variables or apply control conditions to the subjects understudy.

\subsection{Procedure}

When the sampling was over, the EFL students were asked to answer the two above mentioned questionnaires and the writing completion test. Both of the questionnaires were on the basis of a 5-point Likert scale. The score assigned to each item ranged from 1 to 5 . The students were told that there was no right or wrong answer, and that the items just asked about their personal views. They were assured that their scores and responses would be used solely for research purposes. 
Descriptive Statistics were run to determine the mean score of EFL students on self-efficacy, writing strategies and the percentage of learners' correct performance on writing completion task was determined.

The data collected were analyzed using the SPSS statistical package. A frequency analysis, namely the chi square frequency analysis was carried out in order to estimate the likelihood that the variables tend to be systematically related.

\section{Results}

After data were collected, the mean of the four subscales of self-regulation in EFL learners was determined. The mean score $(M)$ of 3.5 or higher for each strategy subscale means High, $M=2.5-3.4$ indicates Medium, and $M=2.4$ or lower denotes Low.

Table 1. Mean of self-efficacy

\begin{tabular}{lcl} 
& Self-efficacy & frequency \\
\cline { 2 - 3 } Iranian & 3.6 & High \\
\hline
\end{tabular}

As Table 1 shows, the mean of self-efficacy beliefs indicate that learners' self-efficacy frequency was high and equated 3.6.

Table 2 shows the writing strategies used by Iranian EFL students. These students frequently plan out how to write, use reference materials, review their work before writing and find different ways to express their ideas. As the total mean in the table suggests these students are high frequency users of writing strategies. There are 4 high frequency mean scores and 6 medium frequency mean scores shown in Table 2.

Table 2. Writing strategies used by Iranian EFL students

\begin{tabular}{|c|c|c|c|c|}
\hline Frequency & Mean & Writing Strategies & $\begin{array}{l}\text { Item } \\
\text { No. }\end{array}$ & Rank \\
\hline High & 4.42 & $\begin{array}{l}\text { Prior designing of the way for writing essays by defining an outline } \\
\text { of the essay first }\end{array}$ & 2 & 1 \\
\hline High & 4.35 & $\begin{array}{l}\text { Using reference materials such as a glossary, a dictionary, or a } \\
\text { thesaurus for finding or verifying words in the target language }\end{array}$ & 7 & 2 \\
\hline High & 3.87 & $\begin{array}{l}\text { Reviewing what has already been written before continuing to write } \\
\text { more }\end{array}$ & 6 & 3 \\
\hline High & 3.62 & $\begin{array}{l}\text { Finding a different way for expressing the idea when not knowing the } \\
\text { correct expression }\end{array}$ & 5 & 4 \\
\hline Medium & 3.45 & $\begin{array}{l}\text { Revising the writing once or twice for improving the language and } \\
\text { content }\end{array}$ & 9 & 5 \\
\hline Medium & 3.42 & Waiting to edit the writing until all the ideas are down on paper & 8 & 6 \\
\hline Medium & 3.34 & Taking class notes in the target language as much as I'm able. & 4 & 7 \\
\hline Medium & 3.32 & Trying to write different kinds of texts in the target language & 3 & 8 \\
\hline Medium & 3.2 & $\begin{array}{l}\text { Trying to get feedback from others, especially native speakers of the } \\
\text { language. }\end{array}$ & 10 & 9 \\
\hline Medium & 2.98 & $\begin{array}{l}\text { Practicing writing the alphabet and/or new words in the target } \\
\text { language }\end{array}$ & 1 & 10 \\
\hline High & 3.59 & MEAN & & \\
\hline
\end{tabular}

As shown in table 3 below the chi-square test indicated that there was a significant relationship between self-efficacy beliefs and writing strategies, $X^{2}(1, n=67)=4.9, p>.05$ (Table 3$)$.

Table 3. Result of Chi-Square Test for Self-efficacy and Writing Strategies Use

\begin{tabular}{ccccc}
\hline $\begin{array}{c}\text { High } \\
\text { self-efficacy }\end{array}$ & $\begin{array}{c}\text { Moderate } \\
\text { self-efficacy }\end{array}$ & total & Chi square & Writing strategies \\
users
\end{tabular}

After determining the relationship between self-efficacy beliefs and writing strategies, the relationship of writing strategies and the correct use of conjunctions in writing task was investigated. First of all, the percentage of correct use of conjunctions in learners was calculated and then the chi-square test was run. The results are demonstrated in table 4. 


\begin{tabular}{|c|c|c|c|c|c|c|}
\hline $25 \%$ & $50 \%$ & $75 \%$ & $100 \%$ & total & $\begin{array}{c}\text { Chi square } \\
x^{2}\end{array}$ & $\begin{array}{c}\text { Use of Writing } \\
\text { Strategies }\end{array}$ \\
\hline 1 & 4 & 28 & 8 & 41 & & High users \\
\hline 2 & 7 & 12 & 5 & 26 & 4.44 & Moderate users \\
\hline 3 & 11 & 40 & 13 & 67 & & Total \\
\hline
\end{tabular}

The result of the chi-square test indicated that there was no significant relationship between writing strategies and correct use of conjunctions, $X^{2}(3, n=67)=4.44, p<.05$ (Table 4$)$.

\section{Discussion}

The obtained results from the present study indicated that there is a significant relationship between the self-efficacy beliefs of the EFL learners and their writing strategies. The means calculated showed that the learners had high selfefficacy beliefs (Mean=3.6), and the results of the writing strategies suggested that the learners are high frequency users of writing strategies.

There are some results found in literature that suggest (Kellogg, 1986) learners' perceptions of the writing enjoyment while they are busy with writing process may sustain them in necessary self-regulatory behaviors. The reason for that may be that if the students believe that they can learn to learn, then they may try to become aware of their cognition. Furthermore, some researchers put emphasis on the awareness of the instructors about the impact of the learners' writing strategies and its relationship with their self-efficacy behaviors (Zimmerman \& Bandura, 1994).

Other studies suggest that it's better for the instructors to consider students' individual characteristics, like writing selfassessment (Palmquist \& Young, 1992), and self-efficacy (Zimmerman \& Bandura, 1994). So, one suggestion for instructors is that they should first try to become familiar with their students learning and self-regulation behaviors and beliefs. This can help them to have a suitable planning for course writing tasks and instruction.

As Winne (1995) and Zimmerman (1990) stated students who check how well they progress and control the effectiveness of their learning methods and strategies, and try hard enough effort to do their academic tasks and show necessary persistence while learning, and have high confidence in their abilities have more regulation of their learning. These students also get better results in language proficiency tests.

\section{Conclusion}

The results of this study presented some information about the learners' self-efficacy beliefs status. It indicated that the learners' self-efficacy beliefs are in a high frequency status. The total self-efficacy mean suggested that the students are highly self-efficacious. The results obtained from the use of writing strategies showed that the EFL learners generally plan out how to write, use reference materials, review their work before writing and find different ways to express their ideas.

As proposed by other researchers, awareness-raising about language learning strategies is viewed as a beneficial and helpful strategy in educational settings. For instance, Kamarul Shukri \& Mohamed Amin (2010) stated that it would be useful and beneficial for students who are not usually aware of the strategies used in language learning to participate in awareness-raising classes in the planning of their courses. Awareness on language learning strategies could improve learners' status by giving them more confidence and self-directed learning. Those learners who actively engage in the process of learning but in fact are not effective users of the writing strategies can be improved by teaching about suitable use of strategies by their teachers (Zhou 2010). So, it is suggested that instructors have a role in making their students familiar with various language learning strategies and dedicate their students the beneficial awareness required for educational context. They can overtly instruct and speak about the strategies and various conjunctions which are used in writing activities.

\section{References}

Adams, G. R. \& Schvaneveldt, J. D. (1985). Understanding research methods. New York: Longman.

Bandura, A. (1977). Self-efficacy: Toward a unifying theory of behavioral change. Psychological Review, 84, $191-215$.

Boekaerts, M. (1999). Self-regulated learning: Where we are today. International Journal of Educational Research, 31 , 445-457.

Boekaerts, M. (2001). Bringing about change in the classroom: strengths and weaknesses of the self-regulated learning approach. Learning and Instruction, 12, 589-604.

Ching, L. (2002). Strategy and self-regulation instruction as contributors to improving students' cognitive model in an ESL program. English for Specific Purposes, 21, 261-289.

Cohen, A. D. 1990. Language Learning: Insights for Learners, Teachers, and Researchers. New York: Newbury House.

Dehghan, M. (2005). The relationship between Iranian EFL learners' goal-oriented and self-regulated learning and their language proficiency. Unpublished MA thesis, Tarbiat Modares University, Tehran.

Ghaemi, F (2009). Writing for IELTS. Sarafraz publications, Iran.

Hartley, J. R., \& Branthwaite, A. (1989). The psychologist as wordsmith: A questionnaire study of the writing strategies of productive /British psychologists. Higher Education, 18, 423-452. doi:10.1007/BF00140748 
Hirose, K., \& Sasaki, M. (1994). Explanatory variables for Japanese students' expository writing in English: An exploratory study. Journal of Second Language Writing, 3, 203-229. doi: 10.1016/1060 3743(94)90017-5

Ilgen, D. R. y Davis, C. A. (2000). Bearing bad news: Reactions to negative performance feedback. Applied Psychology: An International Review, 49(3), 550-565.

Khaldieh, S. A. (2000). Learning strategies and writing processes of proficient

vs. less-proficient learners of Arabic. Foreign Language Annals33, 522-533. doi: 10.1111/j.1944-9720.2000.tb01996.x

Kamarul Shukri \& Mohamed Amin Embi. 2010. Strategi Pembelajaran Bahasa. Kuala Lumpur: Universiti Malaya Press.

Kellogg, R. T. (1988). Attentional overload and writing performance: Effects of rough draft and outline strategies. Journal of Experimental Psychology: Learning, Memory, and Cognition, 14, 355-365. Doi

10.1037/0278-7393.14.2.355.

Martin, J. R. (1992). English Text: System and Structure. Philadelphia/Amsterdam: John Benjamins Publishing Company.

Oxford, R. L. (1990). Language learning strategies: What every teacher should know. New York: Newbury House.

Pamquist, M. \& Young, R. (1992). The noton of giftedness and student expectations about writing. Written Communication, 9,137-169.

Pandian, A. \& Assadi, N. (2010). The ABC's of functional grammar. Malaysia: Oxford Fajar sdn. Bhd.

Pintrich, P., R. (1999). The role of motivation in promoting and sustaining self-regulated learning. International Journal of Educational Research, 31, 459-470.

Torrance, M., \& Jeffery, G. (1999). The cognitive demands of writing Processing capacity and working memory in text production. Amsterdam: Amsterdam University Press.

Torrance, M., G., Thomas, V., \& Robinson, E. J. (2000). Individual differences in undergraduate essay-writing strategies: A longitudinal study Higher Education, 39, 181-200. doi: 10.1023/A:1003990432398

Victori, M. (1997). EFL composing skills and strategies: Four case studies. RESLA, 12, 163-184.

Weinstein, C. E., \& Mayer, R. E. (1986). The teaching of learning strategies. In M. C. Wittrock (Ed.). Handbook of research on teaching (pp. 315-327). New York: McMillan.

Winne, P. H. (1995). Inherent details in self-regulated learning. Educational Psychologist, 30, 173-187.

Yoong L.K. 2010. English Language Learning Strategies used by Form Six Students in Secondary Schools. UKM Master's Thesis.

Zimmerman, B. J. (1990). Self-regulated learning and academic achievement: An overview. Educational Psychologist, 25(1), 3-17.

Zimmerman, B. J. (2000). Attaining self-regulation: A social cognitive perspective. In M. Boekaerts, P. R. Pintrich, \& M. Zeidner, Handbook of Self-regulation. San Diego, CA: Academic Press.

Zimmerman, B. J., \& Bandura, A. (1994). Impact of self-regulatory influences on writing course attainment. American Educational Research Journal, 31, 845-862.

Zimmerman, B. J., \& Schunk, D. H. (1989). Self-regulated learning and academic achievement: Theory, research, and practice. New York: Springer-Verlag.

Zhou Y. 2010. English Language Learning Strategy Use by Chinese Senior High School Students. English Language Teaching. Toronto: Vol. 3, Iss. 4; pg. 152.

\section{Appendix}

\section{Self-efficacy Questionnaire}

Items: Never Seldom Sometimes Often Almost Alway

I believe I will get a high mark in this course. 12345

I'm certain I can comprehend easily the most difficult lessons and issues which are presented in the reading of this course. 12345

I'm confident I can realize the basic ideas instructed in this course. 12345

I'm confident I can realize the most complicated issues which are instructed by the teacher in this course. 12345

I'm confident I can accomplish a high quality job for homework and quizzes in this course. 12345

I expect to do excellent in this course. 12345

I'm certain I can master the skills being taught in this course. 12345

Considering the difficulty of this course, the teacher and my skills, I think I will do well in this course. 12345 